\title{
ALK7 expression in prolactinoma is associated with reduced prolactin and increased proliferation
}

\author{
M Principe1, M Chanal1, V Karam1, A Wierinckx1,2, I Mikaélian', R Gadet1, C Auger1, V Raverot³, E Jouanneau4,5, \\ A Vasiljevic5,6, A Hennino1, G Raverot1,6,7 and P Bertolino'1 \\ ${ }^{1}$ Cancer Research Centre of Lyon (CRCL), INSERM U1052, CNRS UMR5286, Claude Bernard University, Lyon, France \\ 2ProfilXpert, Lyon, France \\ ${ }^{3}$ Laboratoire d'Hormonologie, Centre de Biologie et de Pathologie Est, Hospices Civils de Lyon, Lyon, France \\ ${ }^{4}$ Service de Neurochirurgie, Groupement Hospitalier Est, Hospices Civils de Lyon, Bron, France \\ ${ }^{5}$ Faculté de Médecine Lyon Est, Université Lyon 1, Lyon, France \\ ${ }^{6}$ Department of Pathology, Groupement Hospitalier EST, Hospices Civils de Lyon, University of Lyon, Lyon, France \\ ${ }^{7}$ Department of Endocrinology, Reference Center for Rare Pituitary Disease (HYPO), Groupement Hospitalier EST, Hospices Civils de Lyon, University of \\ Lyon, Lyon, France \\ Correspondence should be addressed to P Bertolino: philippe.bertolino@Inserm.fr
}

\begin{abstract}
Prolactinoma represents the most frequent hormone-secreting pituitary tumours.

These tumours appear in a benign form, but some of them can reach an invasive and aggressive stage through an unknown mechanism. Discovering markers to identify prolactinoma proliferative and invading character is therefore crucial to develop new diagnostic/prognostic strategies. Interestingly, members of the TGF $\beta$-Activin/BMP signalling pathways have emerged as important actors of pituitary development and adult function, but their role in prolactinomas remains to be precisely determined. Here, using a heterotopic allograft model derived from a rat prolactinoma, we report that the Activins orphan type I receptor ALK7 is ectopically expressed in prolactinomas-cells. Through immunohistological approaches, we further confirm that normal prolactinproducing cells lack ALK7-expression. Using a series of human tumour samples, we show that ALK7 expression in prolactinomas cells is evolutionary conserved between rat and human. More interestingly, our results highlight that tumours showing a robust expression of ALK7 present an increased proliferation as address by Ki67 expression and retrospective analysis of clinical data from 38 patients, presenting ALK7 as an appealing marker of prolactinoma aggressiveness. Beside this observation, our work pinpoints that the expression of prolactin is highly heterogeneous in prolactinoma cells. We further confirm the contribution of ALK7 in these observations and the existence of highly immunoreactive prolactin cells lacking ALK7 expression. Taken together, our observations suggest that Activin signalling mediated through ALK7 could therefore contribute to the hormonal heterogeneity and increased proliferation of prolactinomas.
\end{abstract}

Endocrine-Related Cancer (2018) 25, 795-806 


\section{Introduction}

Pituitary tumour is the second most common primary brain tumour in adults (Asa \& Ezzat 2002, Asa et al. 2017). Pituitary tumours are considered as benign, yet their deleterious effects are multiple, ranging from visual disturbance, headaches and infertility through the alteration of metabolic functions due to the hormone they secrete (Asa \& Ezzat 2002, Asa et al. 2017). While most of pituitary tumours have a slow rate of growth, a number of them exhibit an aggressive progression with recurrences. The classification of pituitary neoplasms is misleading because of the simplistic distinction between adenoma and carcinoma, based on a metastatic capacity and a poor predictive value of mitoses and Ki67 or p53 expression (Asa et al. 2017). In addition, the current classification of anterior pituitary neoplasms does not reflect the clinical spectrum of behaviour such as invasion, regrowth of proliferative lesions and persistence of hormone hypersecretion (Raverot et al. 2017). Aggressive pituitary tumours are frequently multi-recurrent and resistant to surgery and radiotherapy. Among all the subtypes of pituitary tumours, prolactinomas, that produce and secrete the hormone prolactin, are the most common functional pituitary tumours. They represent nearly $40 \%$ of all adenomas of the pituitary gland with a prevalence of 100 per million population (Yatavelli \& Bhusal 2017). The prediction of pituitary tumour evolution remains therefore challenging as none of the pathological markers identified so far represent reliable predicting factors of tumour behaviour (Trouillas et al. 2013, Miermeister et al. 2015, Raverot et al. 2015, Saeger et al. 2016).

Over the last few years, members of the transforming growth factor- $\beta /$ Bone Morphogenic Protein (TGF $\beta / B M P$ ) signalling pathway have been suggested to play an important role in promoting pituitary tumour progression and aggressiveness (D'Abronzo et al. 1999, Takeda et al. 2003). TGF $\beta / B M P$ ligands - that comprise TGF $\beta s$, BMPs, Activins/Inhibins and Growth and Differentiation Factors (GDFs) - participate in a wide array of biological processes including cell growth, differentiation, maintenance of homeostatic mechanisms, immune responses as well as tissue remodelling and repair (Massague et al. 2000, Derynck et al. 2001, Wu \& Hill 2009, Xia \& Schneyer 2009). They signal by binding to and activation of binary complexes of type I and type II receptor Serine-Threonine Kinases. Type II receptors bind ligand and then activate type I receptors by phosphorylation. Once activated, type I receptors recruit and phosphorylate second messenger proteins termed 'Smads', which translocate to the nucleus and activate transcription of target genes (Heldin et al. 1997). While no somatic mutations in TGF $\beta /$ BMP type I and type II receptors have so far been found in pituitary adenomas (D'Abronzo et al. 1999), contribution of TGF/BMP ligands and their signalling pathways has been confirmed in prolactinomas. For instance, BMP4 is capable of stimulating the proliferation of GH3 cells, a rat prolactinoma-derived cell line (Paez-Pereda et al. 2003), whereas TGF $\beta$ inhibits this effect and is further capable of repressing prolactin expression in both GH3 and GH4 cells (Delidow et al. 1991, Ramsdell 1991). Contribution of other TGF $\beta /$ BMP ligands such as Activin and Inhibin, originally identified and characterized as FSH-releasing and -inhibiting factors (Bilezikjian et al. 2006) is well established in gonadotroph tumours but less studied in prolactinomas (Takedaetal.2003). This observation is rather surprising as Activin-ligands expression was confirmed by histological approaches in all types of pituitary adenomas including prolactinomas (Alexander et al. 1995, Demura et al. 1996). Previous in vitro work reports that Activins inhibitory effect on GH4 cell proliferation is less effective than the one mediated by TGF $\beta$, while its capacity to enhance adhesion and inhibiting prolactin production is similar (Ramsdell 1991, Lebrun 2009). Expression analysis of Activin cognate type I receptor ALK4 in pituitary tumours has further demonstrated the existence of ALK4 truncated splice variants in non-functioning, GH- and prolactin-producing tumours (Alexander et al. 1996, Zhou et al. 2000). Surprisingly, the expression pattern of ALK7 (the other receptor through which Activins signal) remains unknown in pituitary tumours compared to other TGF/BMP type I receptors (Alexander et al. 1996, D'Abronzo et al. 1999). Knowing that ALK4 truncated variant detected in tumours blocks ALK4 capacity to bind and signal Activins, it further reinforces the need to explore ALK7 expression in those lesions and determine whether ALK7 could actively contribute to pituitary tumorigenesis by rescuing ALK4 deficiency and thus mediating Activin signals in those lesions. Based on this rationale, we thought to investigate whether the expression of Acvr1c that encode the ALK7 receptor was expressed in prolactinomas. Using a heterotopic SMtTW3-allografted rat prolactinoma model (Trouillas et al. 1990) as well as transcriptomic data from the HYPOPRONOS cohort (Raverot et al. 2010) and a novel series of surgically resected pituitary tumours, we found that a subset of prolactinomas highly expresses ALK7. More importantly, we report that the expression of ALK7 in rat is absent in normal prolactin-producing cell and is induced in prolactinomas. We further demonstrate that ALK7 expression is heterogeneous within developed 
tumours, supporting the existence of tumour plasticity in prolactinomas. Finally, our data highlight that detection of high level of ALK7 expression correlates with an increased proliferation and a reduced prolactin immunoreactivity, suggesting a potent association of ALK7 expression and prolactinoma aggressiveness.

\section{Materials and methods}

\section{Human tissues and material}

The study is part of the PITUICARE-Lyon study (clinicaltrials.org NCT02854228). Prolactin pituitary tumours operated by a single surgeon (E J) were classed as non-invasive, invasive and proliferative-invasive upon radiological and histological examination at the time of the first surgery according to the Five-Tiered clinicopathological classification (Trouillas et al. 2013, Raverot et al. 2017). All frozen tumour samples used for gene expression and Formalin-Fixed Paraffin embedded (FFPE) histological samples were obtained from the NeuroBioTec bank (http://www.neurobiotec.net/). Ki67 index was calculated by a semi-quantitative method according to local established clinical routine. Briefly, a total number of Ki67-positive cells were eye-counted out of 10-random microscopic fields and used to determine the percentage of Ki67-positive cells by comparing the average obtained number per field to the total number of cells out of a single field.

\section{Animal model and procedure}

Maintenance of SMtTW3 tumours was done as previously reported (Trouillas et al. 1990). All animal experiments were done in accordance with the guidelines of the European Union and French laws and were validated by the local animal ethical committee (Committee CEEA-55, agreement $n^{\circ}$ DR2014-48 and $n^{\circ}$ DR2017-74). SMtTW3 lineage, that presents high serum PRL levels $(1-150 \mu \mathrm{g} / \mathrm{mL})$, low $\mathrm{GH}$ secretion $(0.4 \mu \mathrm{g} / \mathrm{mL})$ and shares common characteristics and gene expression profile with the human aggressive prolactinomas, was used (Trouillas et al. 1990, Wierinckx et al. 2007). Briefly, SMtTW3 tumours were maintained by serial grafting under the kidney capsule of Wistar/Furth female rats. Six weeks following grafting, tumours were removed, separated from kidney tissue, weighed and prepared immediately according to appropriate scientific procedures. Tumour volume was calculated as follows: $V=\pi / 6 \times L \times W \times H$ (volume $(V)$, height $(H)$, width $(W)$ and length $(L))$.

\section{Immunohistological analysis}

Samples were collected and fixed in $4 \%$ buffered formalin prior paraffin embedding and $3 \mu \mathrm{M}$ sectioning. Human prolactinoma sections were obtained from previous embedded blocs used for diagnostic purposes. Normal rat pituitary glands were obtained from 2- to 3-monthold Wistar/Furth female animals bred under standardized conditions. Immunohistochemical staining (IHC) was revealed with diaminobenzidine (DAB Kit; Vector Laboratories, UK). For all IHC, heat-induced epitope retrieval was performed (antigen-unmasking solution, Vector Laboratories, UK). Immunofluorescence (IF) staining was performed using standard protocol and counterstained with DAPI (DAPI, Vector Laboratories, UK). Used antibodies are as follows: prolactin (Goat, SantaCruz Biotechnology), FSH $\beta$ (Mouse, Immunotech, France), GH (Mouse, Santa-Cruz Biotechnology), ALK7 (Rabbit, Genetex, USA), Ki67 (Goat, Santa-Cruz Biotechnology), P-Smad2 (Rabbit, Chemicon International, USA), cleaved caspase3 (Rabbit, Cell Signaling Technology). Phase contrast and fluorescence images were acquired on an Eclipse-NiE NIKON microscope and analysed using NIS-Elements Software. ALK7 expression was evaluated by eye and classed as Alk7High or Alk7Low lesions/tumour areas based on the intensity of IHC/IF immunoreactivity. Quantifications of IHC and IF staining were done by visual counting using Fiji software. All countings were performed on a minimum of three high-power field pictures obtained from three to seven independent tumours.

\section{RNA extraction/Real-Time quantitative PCR analysis and serum hormonal dosage}

RNAs were extracted using RNeasy-Kits (Qiagen). Real-time PCR analyses were carried out on a Step-One RT-System (Applied Biosystems). Primer-sequences are as follows: Rat Fw-Acvr1c, 5'-ATATGGCTCCCGAAATGCTTG-3', Rat Rv-Acvr1c, 5'-CAAGTCCTCCAACTGAACACCT-3', Rat Fw-Prl, 5'-CATCAATGACTGCCCCACTTC-3', Rat Rv-Prl, 5'-AGCCGCTTGTTTTGTTCCTCA-3', Rat Fw-Tubulin, 5'-TACCCAGACCGCATCATGAA-3', Rat Rv-Tubulin, 5'-GAAAGGGTGGCATTATAGGGC-3', Human Fw-ACVR1C, 5' -ATATGGCTCCTGAAATGCTTG-3', Human Rv-ACVR1C, 5'-CAATTCCTCCGACTGAACACCT-3', Human Fw-GAPDH, 5'-GGTGTGAACCATGAGAAGTATGA-3' and Human Fw-GAPDH, 5'-GAGTCCTTCCACGATACCAAAG-3'. Prolactin concentrations were measured by double antibody radioimmunoassay with the reagents purchased 
at the National Institute of Diabetes and Digestive and Kidney Diseases (PRL rat reagents NIDDK, USA).

\section{Statistical analysis}

Statistical analyses were performed as described in figure legends; unpaired Student's $t$ tests were used unless otherwise indicated. Fisher's exact tests were conducted on contingency tables to explore the relationship between $A C V R 1 C$-high vs low expressing tumours and the proliferative and invading characters of analysed prolactinoma. All analyses were done using Prism6 software (GraphPad).

\section{Results}

\section{ALK7 expression and its downstream Smad} signalling is induced in prolactin-tumour cells

Reported detection of ActivinA and ActivinB in prolactinomas (Alexander et al. 1995, Demura et al. 1996) led us to investigate the expression of their cognate receptor ALK7 in prolactinomas. To do so, we took advantage of the well-established SMtTW3 prolactinoma model based on the allograft of a spontaneous prolactin transplantable tumour from Wistar/Furth Rat (Trouillas et al. 1990). ALK7 expression was analysed by immunohistochemistry (IHC) on a series of histological FFPE-sections obtained from six randomly chosen SMtTW3-tumours. Surprisingly, we found that all analysed samples were showing a positive, yet variable, ALK7 immunoreactivity ranging from a barely detectable (Alk7Low) to a robust (Alk7High) expression (Fig. 1A). Upon ligand stimulation, ALK7 mediates downstream signalling through a direct phosphorylation of Smad proteins (Heldin et al. 1997). Examination of phosphylated Smad2 (P-Smad2) by IHC further confirmed that the robust expression of ALK7 found in the Alk7High lesions was systematically associated with a more active downstream Smad signalling as confirmed by the number of P-Smad2-positive cells (Fig. 1A). As expected, analysis of Smad1/5 phosphorylation that is not mediated by ALK7 did not reveal a correlation with ALK7 expression (Fig. 1A).
A

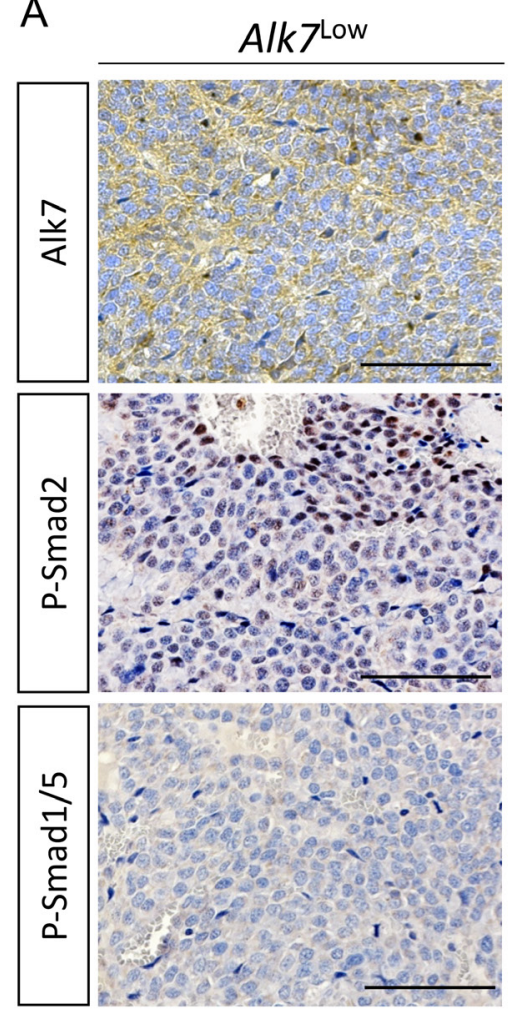

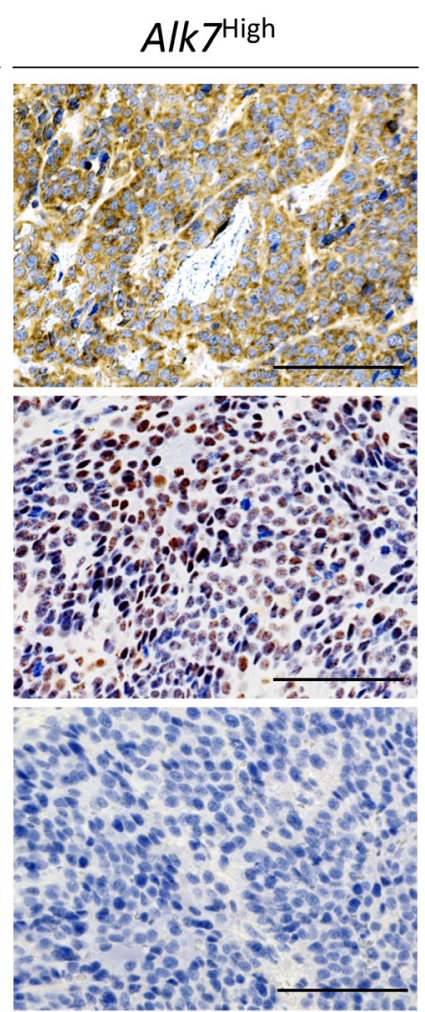

B

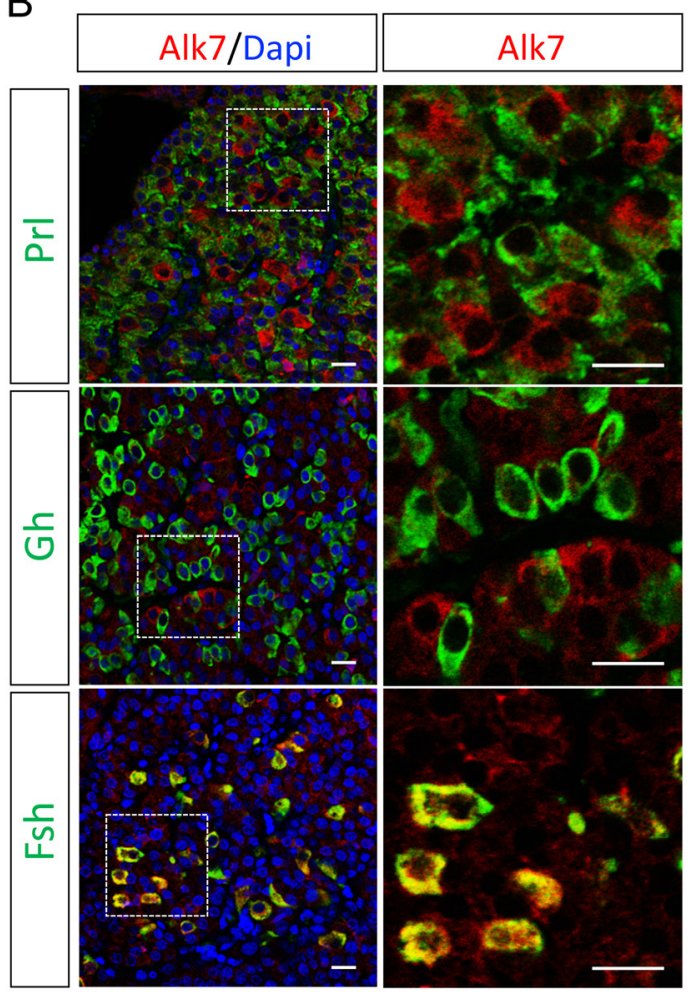

Figure 1

ALK7 expression is induced in rat-SMTtW3 prolactinomas and associated with an active downstream signalling through P-Smad2. (A) Immunohistological analysis of ALK7, P-Smad2 and P-Smad1/5 expression in Alk7High and Alk7Low categorized SMTtW3 tumours. (B) Representative pictures of double immunofluorescence analysis of ALK7 expression in prolactin (Prl), growth hormone (Gh) and follicle-stimulating hormone (Fsh) performed on rat normal pituitary gland. Right panels are magnified view of dashed-line areas. 
Analysis of P-Smad2/ALK7 colocalization performed on $4 \mu \mathrm{M}$-distant serial sections further confirmed that activated signalling was taking place specifically in ALK7 expression areas (Supplementary Fig. 1, see section on supplementary data given at the end of this article). Quantification further confirmed a fourfold increase $(39.2 \pm 5.8 \%$ vs $10.1 \pm 1.9 \%)$ of cells expressing P-Smad2 in ALK7-positive lesions compared to ALK7-negative tumour areas (Supplementary Fig. 1). Interestingly, ALK7 expression was shown to be restricted to FSH-producing gonadotroph cells in the pituitary gland of WT mice (Sandoval-Guzman et al. 2012). Based on this observation, we questioned whether the expression of ALK7 was ectopically induced in prolactin-cells during their tumorigenesis. Therefore, we mapped ALK7 expression in hormone-producing cells within normal rat pituitary gland. Double-IF staining revealed that ALK7 expression was absent in both prolactin- and GH-producing cells, whereas it was detected in FSH-gonadotroph cells (Fig. 1B). Taking together, these observations demonstrate that ALK7 expression is ectopically induced in prolactintumour cells where it associates with a more active Smad2mediated downstream signalling.

\section{Acvr1c shows a heterogenic expression in prolactinomas}

Having found that ALK7 could be detected in a subset of SMTtW3-prolactinoma, we next analysed the expression level of the Acvr1ctranscript that encodes for ALK7 in a larger series of SMTtTW3 tumours. Fourteen new independent tumours were generated from SMtTW3-implants collected 6 weeks after their grafting. Collected tumours were measured and weighed prior to assessing Acvr1c gene expression by quantitative PCR. As found for ALK7, Acvr1c expression was found in all developed prolactinomas with 8 out of 14 tumours showing a higher expression of Acvr $1 c$ (group termed Acvr1 $C^{\mathrm{High}}$ ) (Fig. 2A). Comparative analysis of Acvr1c vs ALK7 expression in matching samples further confirmed a correlation between transcript and protein expression, highlighting that $A c v r 1 c^{\text {High }}$ tumours demonstrate a more homogenous expression of ALK7 compared to Acvr1 $c^{\text {Low }}$ prolactinomas (Supplementary Fig. 2). Whereas circulating concentrations of prolactin and SMTtW3 tumour volumes and weights were showing positive correlation (Supplementary Fig. 3), comparative analysis of Acvr1c expression level with tumour weights and volumes did not reveal any significant correlation (Fig. 2B and C), suggesting that Acvr1c expression levels do not impact these parameters.
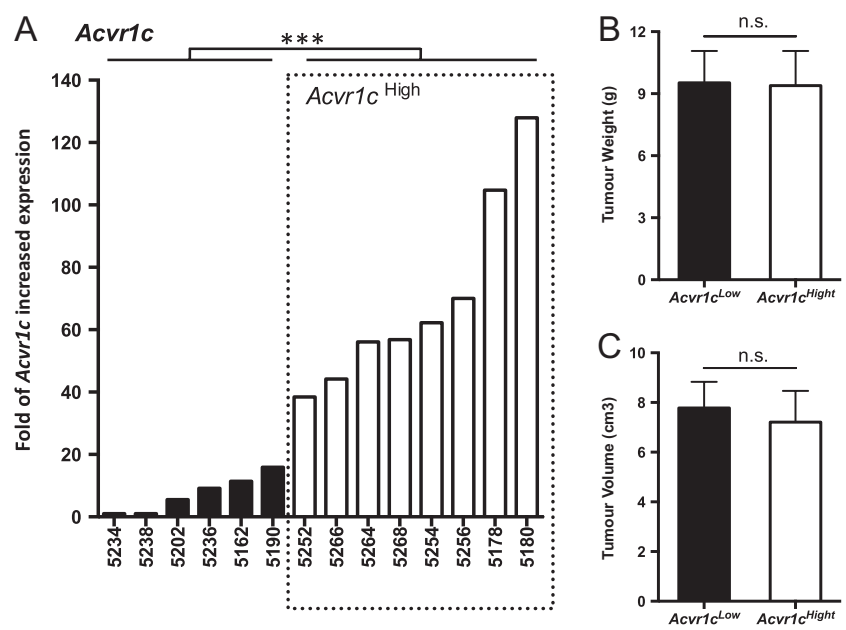

Figure 2

Identification of Acvr1c expression in rat SMTtW3 prolactinomas. (A) Quantification of Acvr1c expression by real-time quantitative PCR. Each number represents an independent SMTtW3-grafted prolactinoma. Acvr1c expression is normalized to Tubulin. Acvr1c expression was compared to the lowest expressing sample as a reference. (B and C) Comparison of weight (B) and volume (C) of SMTtW3 tumours categorized on their high or low expression of Acvr1c as seen in (A) (dashed-area). ${ }^{*} * P<0.001$ by the Student's $t$ test. n.s., not significant.

High level of ALK7 expression in prolactinoma is associated with an increased proliferation and a reduced prolactin synthesis

ALK7 signalling has been reported to contribute to growth arrest in various cells (Jornvall et al. 2001, Munir et al. 2004), while it could also promote cell proliferation in glioblastoma (De Silva et al. 2012). ALK7 was also shown to promote apoptosis in vitro in several cell lines (Munir et al. 2004, Xu et al. 2004, Zhong et al. 2009). Based on these observations, we determined whether a difference of proliferation or apoptosis could be identified in SMtTW3 tumours expressing high or low amounts of Acvr1c. Histological analysis of Ki67 immunoreactivity demonstrated a significant increase of proliferative cells in Acvr1 $1 c^{\text {High }}$ compared to Acvr $1 c^{\text {Low }}$ expressing tumours (Fig. 3A), whereas no difference could be found regarding the number of cleaved-caspase3-positive apoptotic cells (Fig. 3B). Interestingly, Activin signalling inhibits prolactin gene (Prl) expression in vitro in GH4C1 cells (Lacerte et al. 2004). Based on this observation, we hypothesized this effect could also be mediated through ALK7 in prolactinomas. To that extent, we investigated whether ALK7 expression was associated with a reduced $\mathrm{Prl}$ gene expression by tumour cells. Real-time quantitative PCR analysis of Prl performed on Acvr1 $c^{\text {High }}$ and $A c v r 1 C^{\text {Low }}$ tumours confirmed a robust and significant reduction of $\mathrm{Prl}$ expression in Acvr1c $c^{\mathrm{High}}$ prolactinomas 
A

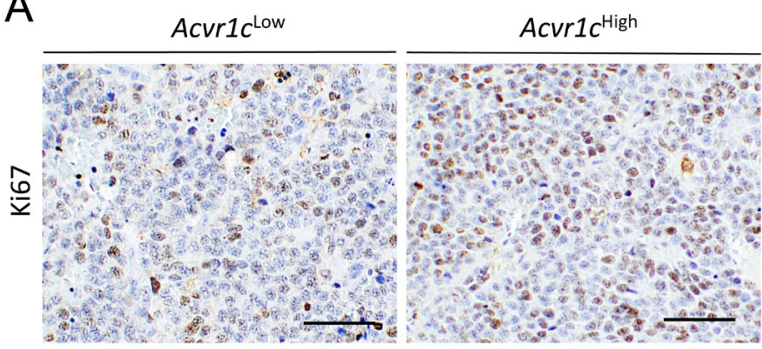

B
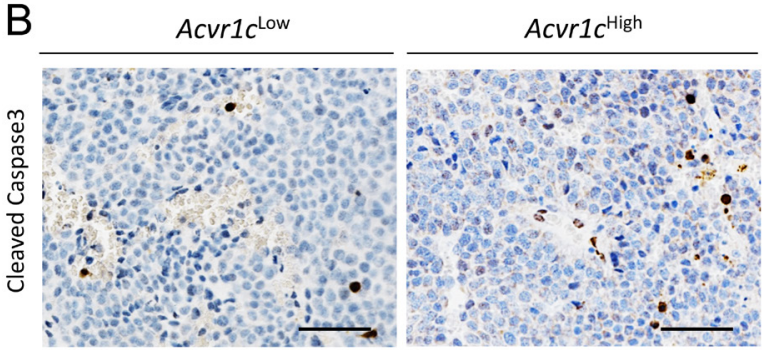
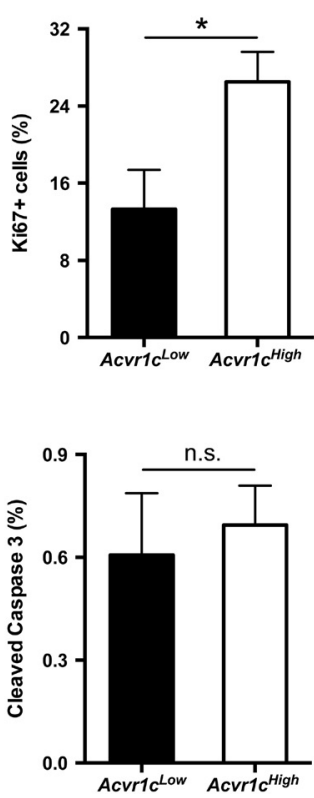

\section{Figure 3}

Acvr1C High SMTtW3 prolactinomas show an increased proliferation. Representative pictures of Ki67 (A) and cleaved-caspase3 (B).

Immunostaining performed on Acvr1 $C^{\text {High }}$ and

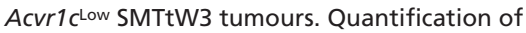
positive cells is shown. Data are represented as means \pm S.E.M. of the percentage of positive cells/ total cells counted from 3 independent fields obtained from 14 independent $A c v r 1 \mathrm{C}^{\mathrm{High}}$ or Acvr $1 c^{\text {Low }}$ tumours. ${ }^{*} P<0.05$ by the Student's $t$ test. n.s., not significant.
(Fig. 4A). A result that further supports a direct role of Activin signalling through Alk7 in the inhibition of $\mathrm{Prl}$ gene transcription. Histological examination of prolactin and ALK7 colocalization further confirmed the observed reduction of prolactin in ALK7-expressing cells (Fig. 5A). Through this analysis, we further highlighted the existence of an important heterogeneity and identified tumour areas expressing large amount of ALK7 and lacking prolactin expression (Fig. 5A, dotted lines). Surprisingly, dosage of circulating prolactin from grafted rat did not reveal a significant difference in circulating prolactin between Acvr1c tumours, while comparative analyses of tumour sizes/weights and circulating prolactin concentrations were consistent (Fig. 4B and Supplementary Fig. 3), suggesting that the overall control of prolactin secretion is conserved in SMtTW3-grafted animal despite the profound loss of prolactin we report.

\section{SMtTW3-tumours show an intra-tumoural heterogeneity that identifies a population of prolactinHigh cells that lack ALK7 and P-Smad2 expression}

Heterogeneity of hormone production in endocrine tumours has been reported but remains poorly explored in prolactinomas. Having found that SMtTW3 tumour cells show variable level of prolactin immunoreactivity, we tested whether ALK7 and its downstream activated effector P-Smad2 colocalize within prolactin tumour cells. As shown in Fig. 5A, the cellular heterogeneity of SMtTW3 tumour was evident, highlighting the existence of prolactin Low/Neg cells and prolactin ${ }^{\text {High }}$ expressing tumours cells. Interestingly, we found the existence of up to $10.1 \pm 1.8 \%$ of prolactin ${ }^{\text {High }}$ cells devoided of ALK7 expression in both Acvr1 $c^{\mathrm{High}}$ and Acvr1 $c^{\mathrm{Low}}$ subgroups of tumours (Fig. 5B). More importantly, $80.2 \pm 4.6 \%$ of cells lacking ALK7 expression and strongly expressing prolactin were also found negative for P-Smad2 expression (Fig. 5C (white arrows)), while $18.4 \pm 4.5 \%$ of prolactin ${ }^{\mathrm{Low} / \mathrm{Neg}}$ cells were positive for P-Smad2, further supporting that ALK7-driven Smad2 phosphorylation could lead to the downregulation of prolactin expression in vivo as suggested by previous in vitro work (Lacerte et al. 2004).

\section{Human proliferative prolactinomas express high amount of ACVR1C}

We next investigated ACVR1C expression in human prolactinomas to validate the relevance of our observations in rat. We first browsed the transcriptomic data available from the HYPOPRONOS study that comprise a series of 31 prolactinomas not treated with dopamine agonists (Raverot et al. 2010). While ACVR1C expression was detected in all control pituitaries, likely due to the presence of ALK7 in gonadotroph cells, prolactinomas were demonstrating a wide range of $A C V R 1 C$ expression level with some lesions showing up to three times the amount of ACVR1C expressed in normal tissues (Fig. 6A). By this mean, we defined an $A C V R 1 C^{\text {High }}$ and an $A C V R 1 C^{\text {Low }}$ group of lesions representing 22.58\% (a: 7/31) and 77.42\% (b: 24/31) of prolactinomas, respectively (Fig. 6A). Analysis of http://erc.endocrinology-journals.org https://doi.org/10.1530/ERC-18-0082
(C) 2018 Society for Endocrinology Published by Bioscientifica Ltd. Printed in Great Britain 


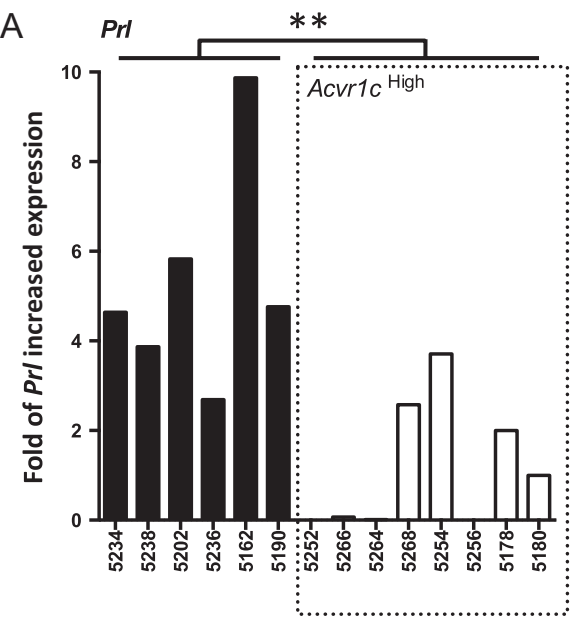

B

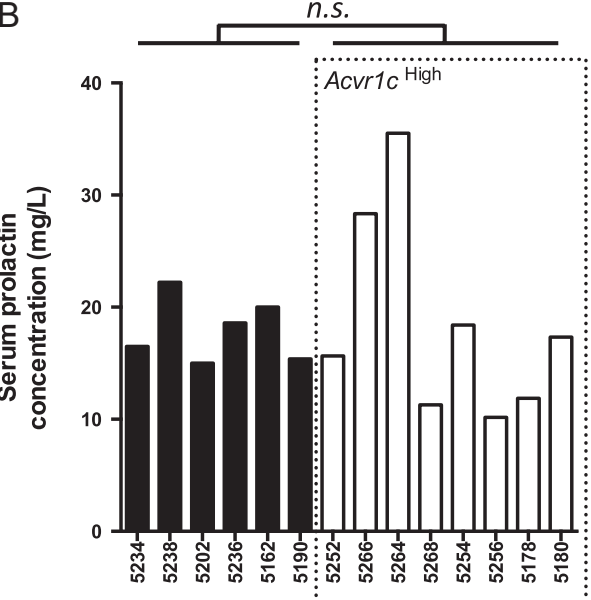

\section{Figure 4}

Acvr1CHigh SMTtW3 prolactinomas are associated with reduced prolactin expression. (A) Quantification of Prl gene expression by real-time quantitative PCR in Acvr1 cHigh or Acvr1 1 Low SMTtW3 tumours. Each number represents an independent SMTtW3-grafted prolactinoma. PrI expression was compared to the highest Acvr1c expressing samples as a reference. (B) Dosage of prolactin from the serum of SMTtW3-grafted rat. Samples issued from $A c v r 1 c^{\text {High }}$ tumours are identified by dashed lines. ${ }^{*} P<0.01$ by the Student's $t$ test. $n$.s., not significant.

gene expression including GH1, FSHb, LHb and the Steroidogenic Factor-1 (SF-1) further confirmed that the detection of $A C V R 1 C$ expression in prolactinomas was not due to a cross-contamination with gonadotroph cells (Supplementary Fig. 4). In order to further validate these observations, ACVR1C expression was analysed from a second randomized series of 18 new prolactinomas obtained from NeuroBioTec Bank. Following RNA extraction and real-time quantitative PCR analysis, we confirmed that $A C V R 1 C$ was heterogeneously expressed in different tumours and further validated that a small subset of prolactinomas $(27.8 \%, 5 / 18)$ were showing a higher expression of $A C V R 1 C$ compared to the highest
ACVR1C expression signal found in gonadotroph tumours (Supplementary Fig. 5). An expression of ACVR1C that was further validated not to be associated with a contamination by gonadotroph or other endocrine cells (Supplementary Fig. 6). We next categorized two groups of prolactinoma based on their ACVR1C normalized expression compared to the mean signal observed in the control group. Using this classification, we further explored whether $A C V R 1 C$ expression could be associated with clinical traits. This analysis demonstrated that $A C V R 1 C$ expression was not correlated with significant changes in tumour volume, $P R L$ gene expression or plasma prolactin concentrations (Fig. 6B, C, D and Table 1). Then, the association of ACVR1C expression with invasive and proliferative character was tested from a total of 38 tumours with available clinical information. While the invasive classification of prolactinomas did not reveal any association with $A C V R 1 C$ expression levels, their proliferative status was significantly correlated with $A C V R 1 C^{\text {High }}$ tumours (Table 1), suggesting that an increased detection of ALK7 expression could represent a relevant marker of prolactinoma proliferation.

\section{Human prolactinomas show a heterogeneous expression of ALK7 that associate with a reduced prolactin immunoreactivity}

We next selected a small series of eight resected prolactinomas to further validate ALK7 expression within tumours. Consistent with the heterogenic expression of ACVR1C, immunohistological analysis confirmed that ALK7 expression was showing a wide range of expression pattern (Fig. 7). While we found that 25\% $(2 / 8)$ of the tumours were showing a barely detectable level of ALK7 (Fig. 7A), most of the analysed sections were immunoreactive for ALK7 (Fig. 7B and C). More importantly and as demonstrated in SMTtW3-prolactinomas, we found ALK7 to be expressed in tumour cells showing reduced amount of prolactin expression, supporting that ALK7 could contribute to the dedifferentiation, hence plasticity of prolactinoma tumour cells (Fig. 7B and C). Examination of the proliferative and invasive status of analysed tumours confirmed that $n=5 / 6$ prolactinomas expressing ALK7 were classed as grade-b/proliferative tumours from a clinical perspective (Fig. 7). Taken together, these observations confirm the heterogeneity of ALK7 expression that exists in prolactinomas, supporting the potent use of ALK7 as a novel marker of prolactinoma tumour cells' proliferation/differentiation status. (c) 2018 Society for Endocrinology Published by Bioscientifica Ltd. Printed in Great Britain 
B
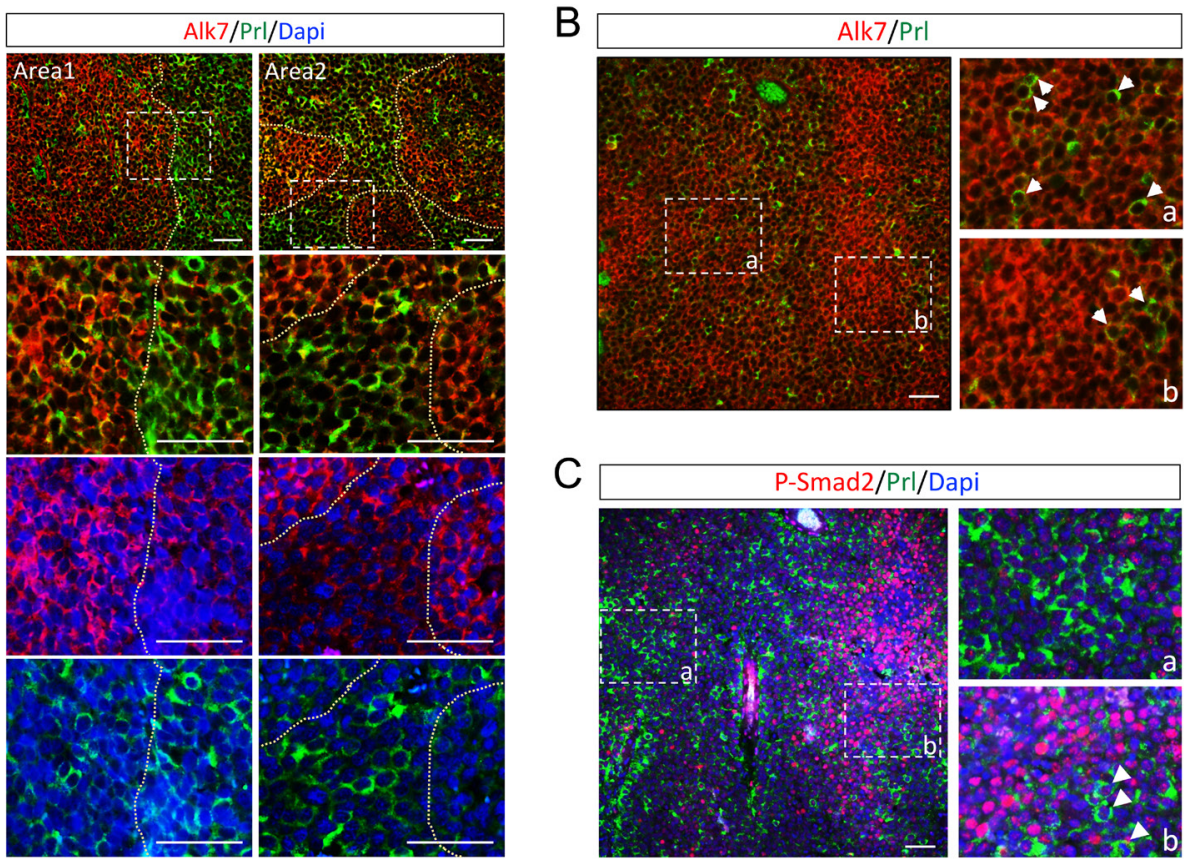

\section{A}

\section{C}

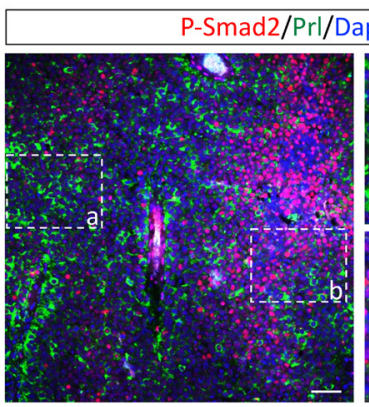

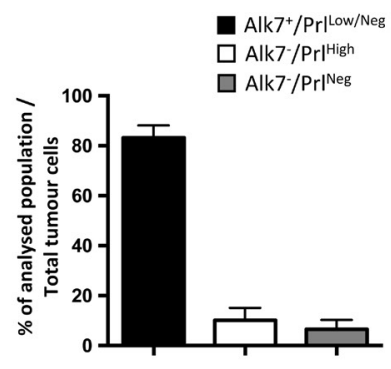
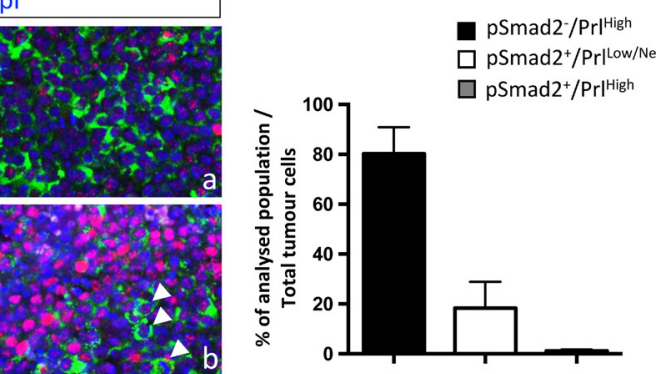

Figure 5

SMTtW3 prolactinomas show a heterogeneous expression of ALK7 and P-Smad2 that identifies a subset of prolactintigh producing cells.

(A) Representative pictures of double immunofluorescence analysis of ALK7/prolactin colocalization in SMTtW3-grafted prolactinomas. Lower panels are magnified view of dashed squares. Dotted lines delineate areas showing Alk7High/prolactin Low and Alk7Low/prolactin High expressions. Right and left panels represent two independent areas of the same tumour. (B and C) Representative pictures of double Immunofluorescence analysis of ALK $7 /$ prolactin (B) and P-Smad2/prolactin (C) colocalization in prolactinomas. Note the existence of an intra-tumoural heterogeneity highlighted by a- and b-dashed squares (B and C). Arrowheads show prolactinHigh cells devoided of ALK7 (A) and P-Smad2 (B). Prl: prolactin. Graphs show quantification of ALK7/Prl (B) and P-Smad2/Prl (C) cell populations performed on at least 3 high-power-fields from 4 independent SMTtW3 tumours.

\section{Discussion}

Aggressive pituitary tumours that are resistant to conventional treatments have a poor prognosis. Developing novel markers and innovative strategies to identify and target their proliferative and invading character represent therefore a major goal to develop new therapeutic and diagnostic/prognostic strategies. Using the SMtTW3-rat model of aggressive prolactinoma, we report for the first time that ALK7 (a receptor for Activins, of which expression is absent in normal prolactinproducing cells) is induced in prolactinoma tumour cells. A mechanism we report to be evolutionary conserved as observed in both rat SMtTW3- and human prolactinomas. More interestingly, our data support that tumours expressing ALK7 present an increased proliferation, pointing ALK7 detection as a potent prolactinoma aggressiveness readout. Beside this observation, our data further highlight that ALK7 expressing tumour cells present a reduced prolactin expression, suggesting that Activin signalling mediated though ALK7 could contribute to a hormonal heterogeneity of prolactinoma likely through cellular plasticity.
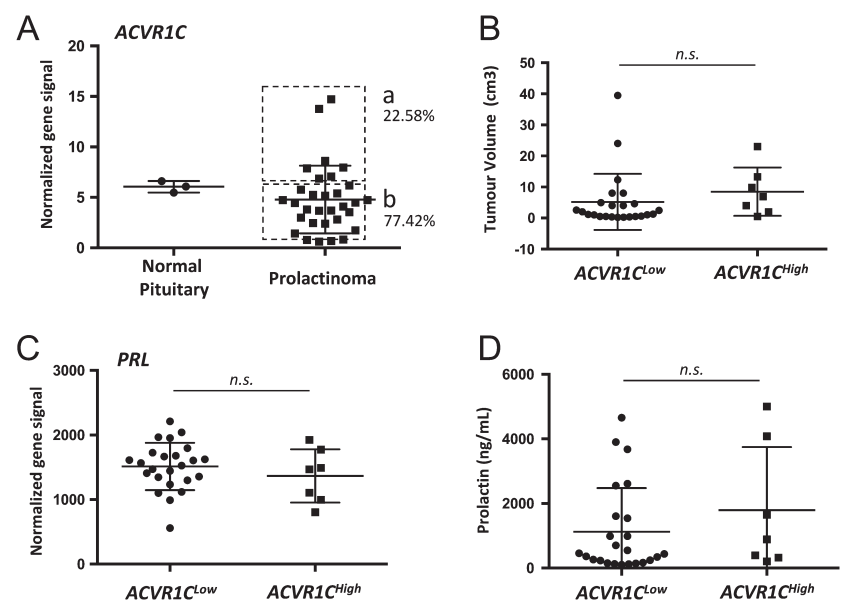

\section{Figure 6}

Retrospective analysis of ACVR1C expression in the HYPOPRONOS human-prolactinoma cohort. (A) Graphical analysis of ACVR1C expression extracted from the HYPOPRONOS dataset, showing ACVR1CHigh (a) and ACVR1CLow (b) grouping (dashed-areas). (B, C and D) Comparison of tumour volume (B), normalized $P R L$ gene expression (C) and circulating Prolactin (D) of patients' prolactinomas categorized by their high or low expression of ACVR1C as seen in (A) (dashed-areas a and b). n.s., not significant (Student $t$ test). 
Table 1 Clinical data of hypopronos-included prolactinomas.

\begin{tabular}{l} 
Sex \\
\hline ACVR1CHigh (7/38) \\
M: 7 \\
F: 1 \\
ACVR1CLow (30/38) \\
M: 15 \\
F: 15
\end{tabular}

\begin{tabular}{|c|c|}
\hline Age & Invasive \\
\hline $\begin{array}{c}47.16 \pm 3.15 \\
49\end{array}$ & $\begin{array}{l}5 / 7(71.42 \%)^{n s} \\
0 / 1\end{array}$ \\
\hline $\begin{array}{l}51.93 \pm 3.27 \\
34.46 \pm 2.63\end{array}$ & $\begin{array}{r}11 / 15(73.33 \%)^{\mathrm{ns}} \\
5 / 15(30.00 \%)^{\mathrm{ns}}\end{array}$ \\
\hline
\end{tabular}

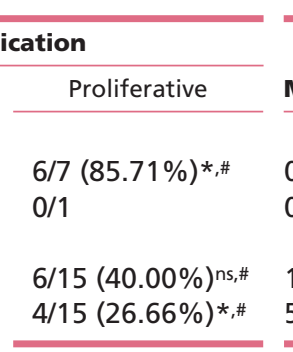

\begin{tabular}{l}
\hline Micro/macro adenoma \\
\hline 0 micro/7 macro \\
0 micro/1 macro \\
1 micro/14 macro \\
5 micro/10 macro
\end{tabular}

\begin{tabular}{|c|c|c|c|}
\hline \multicolumn{4}{|c|}{ 5-Tiered classification } \\
\hline $1 a$ & $1 b$ & $2 a$ & $2 b$ \\
\hline 0 & 2 & 1 & 4 \\
\hline 1 & 0 & 0 & 0 \\
\hline 4 & 0 & 5 & 6 \\
\hline 8 & 2 & 3 & 2 \\
\hline
\end{tabular}

Tumours have been grouped according their high or low ACVR1C expression. The number of tumours belonging to each group is indicated between brackets for each sex. 5-Tiered classification is used to grade tumours as follows: 1, non-invasive; 2, invasive; a, non-proliferative; b, proliferative. Statistical analysis of the contingency table was done using a Fisher's exact test. ${ }^{*} P<0.05$ (males vs females), ${ }^{P} P<0.05$ (both sexes vs both sexes).

$\mathrm{F}$, female; M, male; ns, not significant.

Our work identifies, for the first time, an unexpected expression and the potent role of ALK7 in the tumorigenesis of prolactin-producing pituitary cells. This observation supports the overall importance of TGF $\beta$ superfamily members in pituitary pathological conditions. Indeed, TGF- $\beta$ superfamily members, notably Activin and BMP, have been reported to exert regulatory functions in embryonic and adult pituitary gland (Bilezikjian et al. 2006) but have also been implicated in the pathogenesis of human pituitary adenomas (Danila et al. 2000, Uccella et al. 2000, Takeda et al. 2003). Yet Activin expression is found in all pituitary tumours (Alexander et al. 1995, Demura et al. 1996), little was known, until now, about the impact on their signalling in prolactinomas and the underlying mechanism of their action through ALK4 and ALK7 receptors.

The identification of ALK7 ectopic expression in prolactinomas is an important and unexpected breakthrough. It extents the current known function for ALK7 in the control of $F s h \beta$ transcription within gonadotroph cells (Bernard et al. 2006) and in its contribution to the cyclicity of gonadotropin levels, ovulatory function and LH secretion (SandovalGuzman et al. 2012). Our finding underlines the need to understand the mechanism that drives not only the ectopic but also the heterogeneous expression of ACVR1C
A

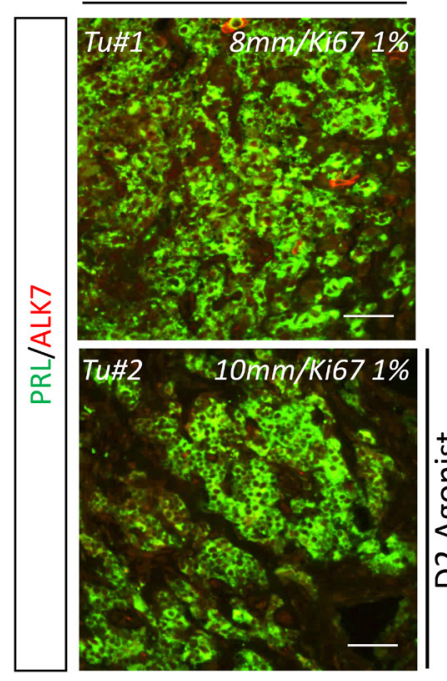

B

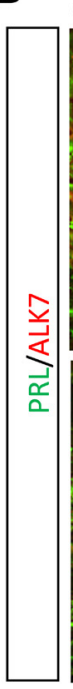

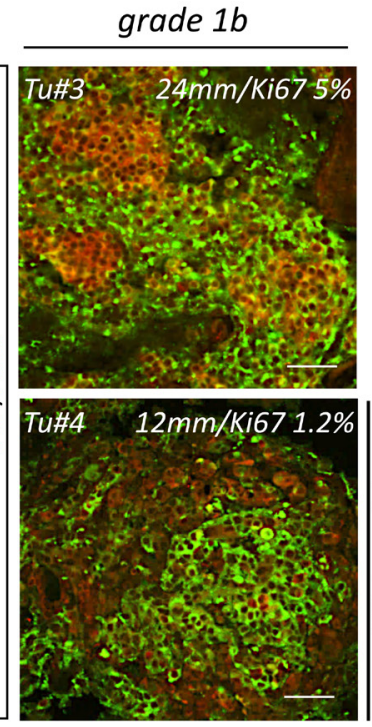

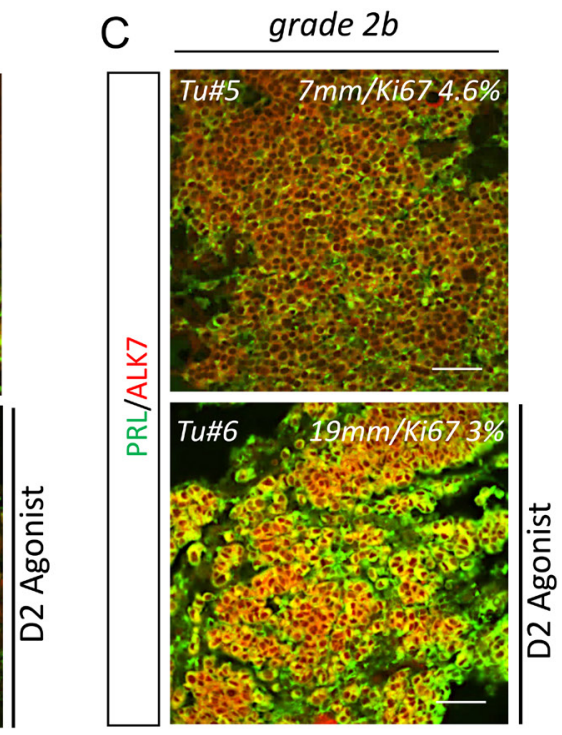

\section{Figure 7}

Human-prolactinoma tumours show a heterogeneous expression of ALK7 that associates with a reduced prolactin expression. Representative pictures of double immunofluorescence analysis of ALK7/prolactin colocalization in a series of randomized prolactinoma sections obtained from patients.

Representative pictures from two independent tumours are shown for grade $1 \mathrm{a}(\mathrm{A}), 1 \mathrm{~b}(\mathrm{~B})$ and $2 \mathrm{~b}(\mathrm{C})$. Grades are as follows: 1 , non-invasive; 2 , invasive; $a$, non-proliferative; $b$, proliferative. Size and Ki67 proliferative indexes are indicated within pictures. Tumours from patients that received dopamine agonist treatments are indicated (DA Agonist). 
and ALK7 in prolactinoma. Interestingly, the promoter and upstream regulatory sequences of ACVR1C contain several H3K27me3 and H3K4me3 methylations sites that are characteristic of bivalent regulatory domains (Pan et al. 2007, Zhao et al. 2007, Ku et al. 2008). This observation reflects the possible existence of an epigenetic control of $A C V R 1 C$ expression through histone modifications. Such epigenetic control remains however to be demonstrated, but it may contribute to the heterogenic expression of ALK7 reported here in prolactinomas. Such hypothesis is consistent with our published work on the epigenetic mechanisms driving ActivinB expression in pancreatic insulinomas (Gherardi et al. 2017) and with the profound epigenetic remodelling that exists in pituitary tumours (Tateno et al. 2010, Pease et al. 2013).

Beside the identification of ALK7 expression in prolactinomas, our data unravel some of its potent downstream effects. For instance, identification of a large number of tumour cells expressing P-Smad2 supports that ALK7 detection is not limited to its sole expression but is also associated to an active signalling. Our observations further support that tumours expressing large amount of ALK7 present an increased proliferation as assessed by Ki67 quantification in rat tumours or retrospective analysis of clinical data from patients. This observation is intriguing, as it suggests that ALK7-signalling promotes an increased proliferation of prolactinoma cells, while previous work presents Activins as cytostatic molecules in GH4C1 cells and a subset of non-functioning pituitary adenoma primary cultures (Danila et al. 2000, Lacerte et al. 2004). Such contradictory observations are also underlined by other studies that demonstrate ALK7 expression to be associated with a respective decreased or increased cell growth in breast cancer or glioblastoma (De Silva et al. 2012, Hu et al. 2017). These discrepancies point out the need to understand how ALK7 and its downstream signalling is capable of promoting cell growth in some tumours including prolactinomas and to further dissect whether these effects are direct or indirect from a molecular perspective.

Besides pointing to a role for ALK7 in controlling the proliferation of prolactinoma cells, our results highlight an important contribution by ALK7 in cellular plasticity as demonstrated by the loss of prolactin production that we report in ALK7 expressing cells. This observation is consistent with the reported capacity of Activin to reduce prolactin expression and secretion in GH4C1 cells in vitro (Ramsdell 1991). To our knowledge, it represents the first demonstration that Activin signalling could regulate prolactin expression in vivo. It also supports an ALK7 implication in the loss of prolactinoma cell maturity, a result reminiscent of the role we recently demonstrated for ActivinB in the loss of $\beta$-cell maturity observed in insulinomas (Ripoche et al. 2015). Interestingly, Activins are detected in the majority of non-functioning tumours, while functioning adenomas showed a significantly lower expression of those ligands (Uccella et al. 2000). These observations suggest that some non-functioning lesions may occur through a dedifferentiation. Determining the exact role of ALK7 and Activin signalling in such process may therefore represent a major advance in comprehending the heterogeneity of pituitary adenoma and the mechanisms driving the development of nonfunctioning tumours. Interestingly, our results further pinpoint the identification of cells devoided of ALK7 expression that show a strong immunoreactivity for prolactin. Identification of these prolactin ${ }^{\text {High }}$ cells is intriguing but strongly supports the idea of an existing intra-tumoural heterogeneity. Determining the origin of these cells and the role of ALK7 in their specification and comprehending whether they are responsible of maintaining a normal homeostasis of prolactin secretion represent a series of major challenges that need to be addressed.

Taken together, our work reinforces the importance of Activin signalling in the biology of pituitary tumours that had been previously reported. Use of ALK7 as a predictive readout of aggressive lesions presenting a higher proliferative rate may therefore represent a promising clinical perspective. More importantly, the differences that exist among tumour cells regarding their prolactin production and the contribution of ALK7 in such heterogeneity should also be considered as an important discovery. Exploring the consequences of activation and inhibition of ALK7 signalling should further help to better comprehend the proliferation and the plasticity of prolactinomas and provide therefore novel diagnostic and therapeutic opportunities for patients.

\section{Supplementary data}

This is linked to the online version of the paper at https://doi.org/10.1530/ ERC-18-0082.

Declaration of interest

The authors declare that there is no conflict of interest that could be perceived as prejudicing the impartiality of the research reported. 


\section{Funding}

This study was supported by the Ligue Contre le Cancer Comité de la Loire (to $P B$ ) et Comité du Rhône (to A H), Association Pour la Recherche sur le Cancer (to $\mathrm{P}$ B) and Société Française d'Endocrinologie (to P B).

\section{Author contribution statement}

P B and G R designed research studies. M P, M C, V K, I M, V R and C A conducted experiments. M P, M C, V K, R G, V R and C A acquired data. $P$ $B, M P, V K, I M, A H, A W$ and $G R$ analysed data and discussed results. A V and $\mathrm{E} J$ provided human material and biopsies. $\mathrm{P} B$ wrote the manuscript.

\section{Acknowledgements}

The authors thank the animal care staff of ALECS-Conventionnel (Lyon, France) for maintenance of the Rat Wistar/Furth strain. We are grateful to Angèle Chamousset for valuable assistance with animal experimentation and Elise Lefebvre for technical help with histological staining.

\section{References}

Alexander JM, Swearingen B, Tindall GT \& Klibanski A 1995 Human pituitary adenomas express endogenous inhibin subunit and follistatin messenger ribonucleic acids. Journal of Clinical Endocrinology and Metabolism 80 147-152. (https://doi.org/10.1210/ jcem.80.1.7829603)

Alexander JM, Bikkal HA, Zervas NT, Laws ER Jr \& Klibanski A 1996 Tumor-specific expression and alternate splicing of messenger ribonucleic acid encoding activin/transforming growth factor-beta receptors in human pituitary adenomas. Journal of Clinical Endocrinology and Metabolism 81 783-790. (https://doi.org/10.1210/ jcem.81.2.8636304)

Asa SL \& Ezzat S 2002 The pathogenesis of pituitary tumours. Nature Reviews Cancer 2 836-849. (https://doi.org/10.1038/nrc926)

Asa SL, Casar-Borota O, Chanson P, Delgrange E, Earls P, Ezzat S, Grossman A, Ikeda H, Inoshita N, Karavitaki N, et al. 2017 From pituitary adenoma to pituitary neuroendocrine tumor (PitNET): an International Pituitary Pathology Club proposal. Endocrine-Related Cancer 24 C5-C8. (https://doi.org/10.1530/ERC-17-0004)

Bernard DJ, Lee KB \& Santos MM 2006 Activin B can signal through both ALK4 and ALK7 in gonadotrope cells. Reproductive Biology and Endocrinology 4 52. (https://doi.org/10.1186/1477-7827-4-52)

Bilezikjian LM, Blount AL, Donaldson CJ \& Vale WW 2006 Pituitary actions of ligands of the TGF-beta family: activins and inhibins. Reproduction 132 207-215. (https://doi.org/10.1530/rep.1.01073)

D'Abronzo FH, Swearingen B, Klibanski A \& Alexander JM 1999 Mutational analysis of activin/transforming growth factor-beta type I and type II receptor kinases in human pituitary tumors. Journal of Clinical Endocrinology and Metabolism 84 1716-1721. (https://doi. org/10.1210/jcem.84.5.5704)

Danila DC, Inder WJ, Zhang X, Alexander JM, Swearingen B, HedleyWhyte ET \& Klibanski A 2000 Activin effects on neoplastic proliferation of human pituitary tumors. Journal of Clinical Endocrinology and Metabolism 85 1009-1015. (https://doi. org/10.1210/jcem.85.3.6473)

De Silva T, Ye G, Liang YY, Fu G, Xu G \& Peng C 2012 Nodal promotes glioblastoma cell growth. Frontiers in Endocrinology 3 59. (https://doi. org/10.3389/fendo.2012.00059)

Delidow BC, Billis WM, Agarwal P \& White BA 1991 Inhibition of prolactin gene transcription by transforming growth factor-beta in GH3 cells. Molecular Endocrinology 5 1716-1722. (https://doi. org/10.1210/mend-5-11-1716)
Demura R, Kubo O, Suzuki T, Yajima R, Tajima S, Takakura K, Demura H, Aiba M \& Eto Y 1996 Demonstration of activin in normal pituitary and in various human pituitary adenomas by immunohistochemistry. Endocrine Journal 43 429-432. (https://doi. org/10.1507/endocrj.43.429)

Derynck R, Akhurst RJ \& Balmain A 2001 TGF-beta signaling in tumor suppression and cancer progression. Nature Genetics 29 117-129. (https://doi.org/10.1038/ng1001-117)

Gherardi S, Ripoche D, Mikaelian I, Chanal M, Teinturier R, Goehrig D, Cordier-Bussat M, Zhang CX, Hennino A \& Bertolino P 2017 Menin regulates Inhbb expression through an Akt/Ezh2-mediated H3K27 histone modification. Biochimica et Biophysica Acta 1860 427-437. (https://doi.org/10.1016/j.bbagrm.2017.02.003)

Heldin CH, Miyazono K \& ten Dijke P 1997 TGF-beta signalling from cell membrane to nucleus through SMAD proteins. Nature 390 465-471. (https://doi.org/10.1038/37284)

Hu T, Su F, Jiang W \& Dart DA 2017 Overexpression of activin receptorlike kinase 7 in breast cancer cells is associated with decreased cell growth and adhesion. Anticancer Research 37 3441-3451. (https://doi. $\operatorname{org} / 10.21873 /$ anticanres.11712)

Jornvall H, Blokzijl A, ten Dijke P \& Ibanez CF 2001 The orphan receptor serine/threonine kinase ALK7 signals arrest of proliferation and morphological differentiation in a neuronal cell line. Journal of Biological Chemistry 276 5140-5146. (https://doi.org/10.1074/jbc. M005200200)

$\mathrm{Ku}$ M, Koche RP, Rheinbay E, Mendenhall EM, Endoh M, Mikkelsen TS, Presser A, Nusbaum C, Xie X, Chi AS, et al. 2008 Genomewide analysis of PRC1 and PRC2 occupancy identifies two classes of bivalent domains. PLoS Genetics 4 e1000242. (https://doi. org/10.1371/journal.pgen.1000242)

Lacerte A, Lee EH, Reynaud R, Canaff L, De Guise C, Devost D, Ali S, Hendy GN \& Lebrun JJ 2004 Activin inhibits pituitary prolactin expression and cell growth through Smads, Pit-1 and menin. Molecular Endocrinology 18 1558-1569. (https://doi.org/10.1210/ me.2003-0470)

Lebrun JJ 2009 Activin, TGF-beta and menin in pituitary tumorigenesis. Advances in Experimental Medicine and Biology 668 69-78.

Massague J, Blain SW \& Lo RS 2000 TGFbeta signaling in growth control, cancer, and heritable disorders. Cell 103 295-309. (https:// doi.org/10.1016/S0092-8674(00)00121-5)

Miermeister CP, Petersenn S, Buchfelder M, Fahlbusch R, Ludecke DK, Holsken A, Bergmann M, Knappe HU, Hans VH, Flitsch J, et al. 2015 Histological criteria for atypical pituitary adenomas - data from the German pituitary adenoma registry suggests modifications. Acta Neuropathologica Communications 3 50. (https://doi.org/10.1186/ s40478-015-0229-8)

Munir S, Xu G, Wu Y, Yang B, Lala PK \& Peng C 2004 Nodal and ALK7 inhibit proliferation and induce apoptosis in human trophoblast cells. Journal of Biological Chemistry 279 31277-31286. (https://doi. org/10.1074/jbc.M400641200)

Paez-Pereda M, Giacomini D, Refojo D, Nagashima AC, Hopfner U, Grubler Y, Chervin A, Goldberg V, Goya R, Hentges ST, et al. 2003 Involvement of bone morphogenetic protein 4 (BMP-4) in pituitary prolactinoma pathogenesis through a Smad/estrogen receptor crosstalk. PNAS 100 1034-1039. (https://doi.org/10.1073/ pnas.0237312100)

Pan G, Tian S, Nie J, Yang C, Ruotti V, Wei H, Jonsdottir GA, Stewart R \& Thomson JA 2007 Whole-genome analysis of histone H3 lysine 4 and lysine 27 methylation in human embryonic stem cells. Cell Stem Cell 1 299-312. (https://doi.org/10.1016/j.stem.2007.08.003)

Pease M, Ling C, Mack WJ, Wang K \& Zada G 2013 The role of epigenetic modification in tumorigenesis and progression of pituitary adenomas: a systematic review of the literature. PLOS ONE $\mathbf{8}$ e82619. (https://doi.org/10.1371/journal.pone.0082619)

Ramsdell JS 1991 Transforming growth factor-alpha and -beta are potent and effective inhibitors of GH4 pituitary tumor cell proliferation. (c) 2018 Society for Endocrinology Published by Bioscientifica Ltd. Printed in Great Britain 
Endocrinology 128 1981-1990. (https://doi.org/10.1210/endo-128-41981)

Raverot G, Wierinckx A, Dantony E, Auger C, Chapas G, Villeneuve L, Brue T, Figarella-Branger D, Roy P, Jouanneau E, et al. 2010 Prognostic factors in prolactin pituitary tumors: clinical, histological, and molecular data from a series of 94 patients with a long postoperative follow-up. Journal of Clinical Endocrinology and Metabolism 95 1708-1716. (https://doi.org/10.1210/jc.2009-1191)

Raverot G, Vasiljevic A, Jouanneau E \& Trouillas J 2015 A prognostic clinicopathologic classification of pituitary endocrine tumors. Endocrinology and Metabolism Clinics of North America 44 11-18. (https://doi.org/10.1016/j.ecl.2014.10.001)

Raverot G, Dantony E, Beauvy J, Vasiljevic A, Mikolasek S, BorsonChazot F, Jouanneau E, Roy P \& Trouillas J 2017 Risk of recurrence in pituitary neuroendocrine tumors: a prospective study using a fivetiered classification. Journal of Clinical Endocrinology and Metabolism 102 3368-3374. (https://doi.org/10.1210/jc.2017-00773)

Ripoche D, Charbord J, Hennino A, Teinturier R, Bonnavion R, Jaafar R, Goehrig D, Cordier-Bussat M, Ritvos O, Zhang CX, et al. 2015 ActivinB is induced in insulinoma to promote tumor plasticity through a beta-cell-induced dedifferentiation. Molecular and Cellular Biology 36 756-764. (https://doi.org/10.1128/MCB.00930-15)

Saeger W, Petersenn S, Schofl C, Knappe UJ, Theodoropoulou M, Buslei R \& Honegger J 2016 Emerging histopathological and genetic parameters of pituitary adenomas: clinical impact and recommendation for future WHO classification. Endocrine Pathology 27 115-122. (https://doi.org/10.1007/s12022-016-9419-6)

Sandoval-Guzman T, Gongrich C, Moliner A, Guo T, Wu H, Broberger C \& Ibanez CF 2012 Neuroendocrine control of female reproductive function by the activin receptor ALK7. FASEB Journal 26 4966-4976. (https://doi.org/10.1096/fj.11-199059)

Takeda M, Otsuka F, Suzuki J, Kishida M, Ogura T, Tamiya T \& Makino H 2003 Involvement of activin/BMP system in development of human pituitary gonadotropinomas and nonfunctioning adenomas. Biochemical and Biophysical Research Communications 306 812-818. (https://doi.org/10.1016/S0006291X(03)01052-0)

Tateno T, Zhu X, Asa SL \& Ezzat S 2010 Chromatin remodeling and histone modifications in pituitary tumors. Molecular and Cellular Endocrinology 326 66-70. (https://doi.org/10.1016/j. mce.2009.12.028)

Trouillas J, Girod C, Claustrat B, Joly-Pharaboz MO \& Chevallier P 1990 Spontaneous prolactin transplantable tumor in the Wistar/Furth rat
(SMtTW): a new animal model of human prolactinoma. Cancer Research 50 4081-4086.

Trouillas J, Roy P, Sturm N, Dantony E, Cortet-Rudelli C, Viennet G, Bonneville JF, Assaker R, Auger C, Brue T, et al. 2013 A new prognostic clinicopathological classification of pituitary adenomas: a multicentric case-control study of 410 patients with 8 years postoperative follow-up. Acta Neuropathologica 126 123-135. (https://doi. org/10.1007/s00401-013-1084-y)

Uccella S, La Rosa S, Genasetti A \& Capella C 2000 Localization of inhibin/ activin subunits in normal pituitary and in pituitary adenomas. Pituitary 3 131-139. (https://doi.org/10.1023/A:1011431123208)

Wierinckx A, Auger C, Devauchelle P, Reynaud A, Chevallier P, Jan M, Perrin G, Fevre-Montange M, Rey C, Figarella-Branger D, et al. 2007 A diagnostic marker set for invasion, proliferation, and aggressiveness of prolactin pituitary tumors. Endocrine-Related Cancer 14 887-900. (https://doi.org/10.1677/ERC-07-0062)

Wu MY \& Hill CS 2009 TGF-beta superfamily signaling in embryonic development and homeostasis. Developmental Cell 16 329-343. (https://doi.org/10.1016/j.devcel.2009.02.012)

Xia Y \& Schneyer AL 2009 The biology of activin: recent advances in structure, regulation and function. Journal of Endocrinology 202 1-12. (https://doi.org/10.1677/JOE-08-0549)

Xu G, Zhong Y, Munir S, Yang BB, Tsang BK \& Peng C 2004 Nodal induces apoptosis and inhibits proliferation in human epithelial ovarian cancer cells via activin receptor-like kinase 7. Journal of Clinical Endocrinology and Metabolism 89 5523-5534. (https://doi. org/10.1210/jc.2004-0893)

Yatavelli RKR \& Bhusal K 2017 Prolactinoma. In StatPearls. Treasure Island, FL, USA: StatPearls Publishing LLC.

Zhao XD, Han X, Chew JL, Liu J, Chiu KP, Choo A, Orlov YL, Sung WK, Shahab A, Kuznetsov VA, et al. 2007 Whole-genome mapping of histone $\mathrm{H} 3 \mathrm{Lys} 4$ and 27 trimethylations reveals distinct genomic compartments in human embryonic stem cells. Cell Stem Cell $\mathbf{1}$ 286-298. (https://doi.org/10.1016/j.stem.2007.08.004)

Zhong Y, Xu G, Ye G, Lee D, Modica-Amore J \& Peng C 2009 Nodal and activin receptor-like kinase 7 induce apoptosis in human breast cancer cell lines: role of caspase 3. International Journal of Physiology, Pathophysiology and Pharmacology 1 83-96.

Zhou Y, Sun H, Danila DC, Johnson SR, Sigai DP, Zhang X \& Klibanski A 2000 Truncated activin type I receptor Alk4 isoforms are dominant negative receptors inhibiting activin signaling. Molecular Endocrinology 14 2066-2075. (https://doi.org/10.1210/ mend.14.12.0570)

Received in final form 18 April 2018

Accepted 16 May 2018 http://erc.endocrinology-journals.org https://doi.org/10.1530/ERC-18-0082 (c) 2018 Society for Endocrinology Published by Bioscientifica Ltd. Printed in Great Britain 